\title{
Mobility and Habitation Adaptation: A Case Study Migrant Muslims in Lanzhou City, China
}

\author{
Xiang $\mathrm{Gao}^{1}$, Huaxiao $\mathrm{Ma}^{1}$, \& Hao Zhao ${ }^{1}$ \\ ${ }^{1}$ Lanzhou University, China \\ Correspondence: Xiang Gao, Lanzhou University, China.
}

Received: May 14, 2018

doi:10.11114/ijsss.v6i7.3269
Accepted: June 19, $2018 \quad$ Available online: June 22, 2018

URL: https://doi.org/10.11114/ijsss.v6i7.3269

\begin{abstract}
Viewed from a spatial perspective and based on information from 1467 surveys samples conducted from 2015 to 2016, a case study of mobility and habitation adaption of migrant Muslims in Lanzhou city of China has been carried out using ArcGIS. The results show that: 1) the sources of migrant Muslims in Lanzhou are dominated by two ethnic regions, Linxia Autonomous Hui Prefecture approximately $160 \mathrm{~km}$ from Lanzhou, and Tianshui Zhangjiachuan Autonomous County $380 \mathrm{~km}$ from Lanzhou. Together the regions account for $56.5 \%$ of the sample respondents. To a great extent, the ethnic homogeneity related Muslims between the origin and Lanzhou city helps push migration; 2) the 40 sending regions from which migrant Muslims originate display a "core-margin" and "string of bead" spatial structure, and most sending regions are scattered within $20 \mathrm{~km}$ along the principal corresponding artery leading into \& out of Lanzhou. Traffic improvement can lead to some changes to the double "core-margin" structure from basic "core-margin" to spindly "core-margin" along the corresponding artery; (3) the traditional pattern of "dwell and work around mosque" of migrant Muslims in Lanzhou is weakening. On the one hand, $46.2 \%$ of migrant Muslims dwell away and 50.1\% of them work away from mosque; on the other hand from July 2015 to July 2016123 migrants removed from their original dwelling places and 197 migrants from their original places of working around mosque to be scattered in Lanzhou city. The reason for decentralization includes the increasing spatial spread of Muslim-culture-focused catering, the weakening of traditional ethnic consciousness and personal independence.
\end{abstract}

Keywords: migrant Muslims, mobility, habitation adaption, Kernel Density Estimate (KDE), Lanzhou city

\section{Introduction}

For the past decades, rural-urban migration has been a major social development in China, together with dramatic economic reform and rapid demographic transition. More and more migrant Muslims like the Han people, constantly crowd into large cities, Approximately three million migrant Muslims reside in China (Jin, 2009), and most of them live in the western lager cities of China such as Xi'an, Lanzhou, Urumqi. So it is representative to do a case research into Lanzhou city. Molility and adaption of migrant Muslims with unique religious culture, ethnic customs and ethnic consciousness are more complicated than those of the Han migrants who are the majority of floating population in China, which have been becoming a key issue confronted by researchers..

The demographer Everett S. Lee (1966) identified "the scale of migrants is in direct proportion to the heterogeneity between regions or crowds, in other words, the more heterogeneity, the more volume of migrants." The heterogeneity between regions present with unbalanced economic and social development, and the heterogeneity between crowds usually refers to cultural difference. Most Chinese scholars agree that the disparities between city and countryside such as rural unattractive climate, poor economy, uncongenial social surroundings and unjust laws, all have produced producing currents of migration. But this may be true for the Han migrants; however, it is untrue for ethnic migrants. As far migrant Muslims the homogeneity in terms of identical ethnic religious culture, customs and lifestyle between sending region and receiving regions has become a vital social factor that provokes their migration. According to Chinese sociologist Rong Ma (2004), "migration trends toward places inhabited by the same ethnic group in the hope of culture attribute and communication convenience. The small community dwelled by the same ethnic people can be developed autonomously which benefits to keep their traditional religion, custom and legitimate rights, and to help each other." According to R.L. Burford (1962, p35), psychological distance is more important than geographical distance among the factors that determine migration. Aside from homogeneity, the proximity to religious activities is vital for 
Muslims to urge their migration.

As far as origins of migrants is concerned, migrants in metropolises of China are both from all over the country, and the majority of them from near provinces or cities (Qian, 2003; Lu,2005; Bai,2007). But the study by Lu Qi et al. (2006) proved that the volume of migrants from remote areas is constantly growing instead of the origin pattern with a domination of migrants from North China. Shanhai city(Ding, 2005), and Guangzhou city (Yao et al. 2008) exhibit similar feature. Compared to eastern metropolises of China, western larger cities of China often have most migrants within the province (Tang,2006; Gao ,2010).

As for settlement pattern of migrant's American researcher Min Zhou (1992) argued the establishment of Ghettos in Peru's capital city of Lima. Chigago school class development laws into different patterns such as pattern of concentric circle(Burgess,1925), sector pattern (Hoyt,1939) and polykaryon pattern(Murdie,1969). Studies on housing search get involved in housing search space model( namely range attenuation model and area-based search model), housing search cognitive space (Adams, 1969; Tuan, 1975) and collection of vacant house information (Michelson,1977).

Studies by Chinese scholars related to spatial pattern of migrant's settlement can fall into the following three categories: firstly studies on spatial variation characteristics of their settlement in Beijing(Wu,1999;Wang,2008), Shanghai(Wu 2003) and Nanjing city(Bai,2007); secondly studies on housing location determination or transfer covering common orientation to it(Qian, 2003), dwelling pattern in Beijing (Liu,1999) and housing location preference (Zhang,2003;Liu,2010); thirdly studies on spatial relationship between settlement and employment involving organization pattern and spatial change in Guangzhou city (Zhou,2010), residential suburbanization, spatial mismatch(Song,2010) and influence factors close to determination based on commuting time in Beijing (Zheng, 2009) and spatial balance between settlement and employment in Shanghai(Song,2008).

The purpose of this paper is to reveal the mobility field of migrant Muslims before they enter Lanzhou city and their dwelling pattern after they settle down in Lanzhou city. To some extent, the paper would improve immigration "push-pull" theory by verifying that the homogeneity in terms of identical ethnic religious culture, customs and lifestyle has pushed Muslims even more to migrate and the ethnic space theory by clarifying that the traditional spatial pattern of the "dwell and work around mosques" regarding migrant Muslims is steadily weakening.

\section{Study Area}

The study area, Lanzhou city, is one of typical larger city inhabited by many ethnic groups in Northwest China. As the capital of Gansu Province and transport hub in Northwest China, the city covers approximately $13085.6 \mathrm{~km}^{2}$ with a census population of 3.83 million in 2016(Lanzhou's Statistical Bureau). It comprises five urban districts (Chengguan, Qilihe, Anning, Xigu, and Honggu) and three counties (Yuzhong, Yongdeng, and Gaolan). Further five urban districts are divided into two parts, namely main city zone( also intra-urban districts) including Chengguan, Qilihe, Anning and Xigu district and exurban district including Honggu (Figure1). Now 37 minorities reside with a population of 116,200 in 2016, accounting for 3.6\% of the total population in Lanzhou. 10 minorities of them, mainly Hui, Dongxiang, Shala, Baoan, Uygur, and Kazak, profess Islam. These 10 minorities have a population of 110,000, accounting for $94.7 \%$ of Lanzhou's minority population (Lanzhou's Statistical Bureau). Moreover, approximately 72,000 migrant Muslims reside in Lanzhou, 54,000 of which are located in the main city zone and 18000 of which are located in outlying Honggu district and three counties including Yongdeng, Gaolan and Yuzhong (Lanzhou Committee on Population in 2016). 


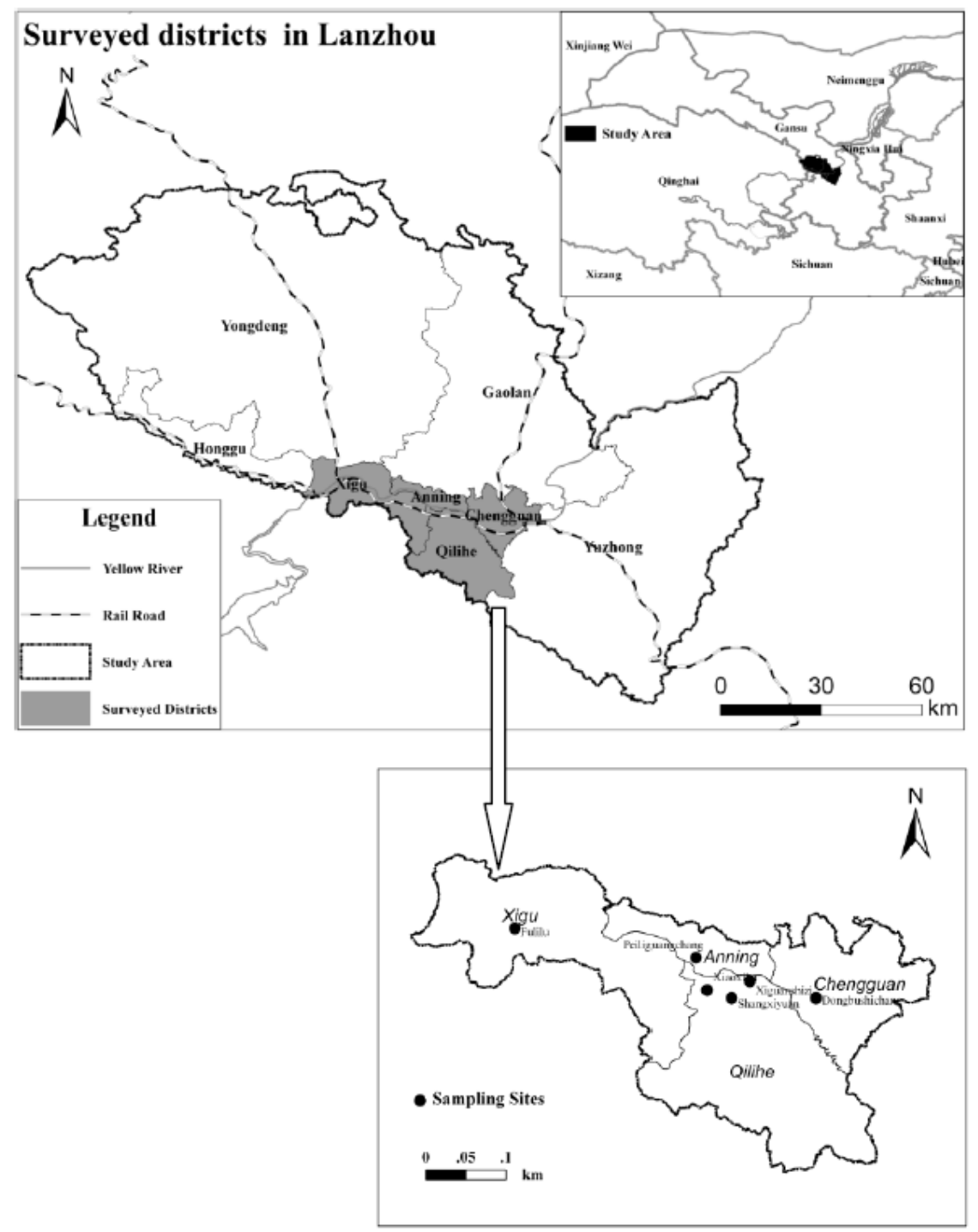

Figure 1. A sketch Map of study area (top). Sampling sites in surveyed districts (bottom)

\section{Methodology}

\subsection{Data Collection}

In 2016 there are much population density differences of Han and non-Han among five districts and three counties of Lanzhou city (Figure 2). On the one hand population densities of both Han and non-Han in main urban zone are much more than those in outlying districts, on the other hand the maximum of population densities of both Han and non-Han occur in Chengguan district of Lanzhou. So the main urban zone is chosen as the surveyed area in this paper.

Historically, migrant Muslims in Lanzhou are mainly concentrated in several areas of downtown, including Xiguanshizi and Dongbushichang in Chengguan district, Xiaoxihu and Shangxiyuan in Qilihe district, Peiliguangchang in Anning district and Fulilu in Xigu distirct. Thus, the migrant Muslims found in these six areas were selected for the detailed survey (Figure 1). The questionnaire was primarily designed to gather information on them. However, the practical data collection may change due to the different circumstances of migrant Muslims in the six areas above. Particularly, Xiaoxihu and Shangxiyuan are areas wherein the migrant Muslims are made up of a variety of people. Thus, stratified random sampling for the questionnaire was utilized with stratification based on age, gender and occupation. Multistage sampling was conducted to collect information selected of migrant Muslims in Xiguanshizi and Dongbushichang, where they show many clusters representing different working places. The survey begins by dividing the two areas into several 'collection blocks', then the working places are listed within each selected block. In the remaining two areas, Peiliguangchang and Fulilu, where most migrant Muslims set up small businesses with strong shifting, the questionnaire 
was distributed using simple random sampling method.
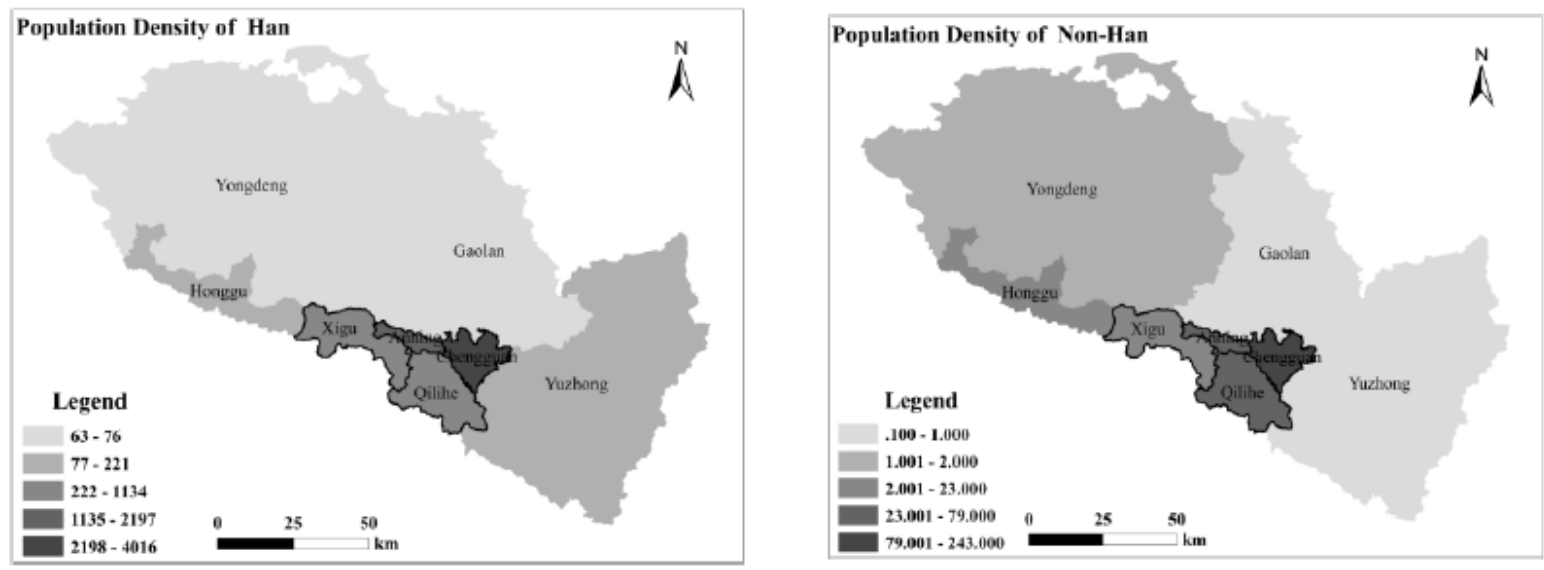

Figure 2. Population densities of Han and non-Han among five districts and three counties of Lanzhou city

From March 2016 to March 2016, 1700 questionnaires were sent out and 1512 questionnaires were returned, representing an effective recovery rate of $88.94 \%$. In all, 333 questionnaires were eliminated from our analysis due to incomplete information as other problems; thus, 1467 questionnaires were finally selected representing an effective percentage of $86.3 \%$. The questionnaire involved queries on many aspects relating to migrant Muslims, such as basic information (gender, age, marital status, educational level), population flow field and urban adaptation.

\subsection{Multiple Characteristics of Migrant Muslims}

Of 1467 survey respondents 880 males and 587 females; $86.5 \%$ of them married. Most of them fall into the elderly category, and migrants at different ages showed different educational background, occupation and income (Table 1).

Table 1. Descriptive Statistic for Survey Samples in Lanzhou（N=1467）

\begin{tabular}{|c|c|c|c|c|c|c|c|c|c|c|}
\hline \multirow[b]{3}{*}{ Variable } & \multicolumn{10}{|c|}{ Age, years } \\
\hline & \multicolumn{2}{|c|}{$\leq 20(n=207)$} & \multicolumn{2}{|c|}{$21-30(n=173)$} & \multicolumn{2}{|c|}{$31-40(n=587)$} & \multicolumn{2}{|c|}{$41-50(n=475)$} & \multicolumn{2}{|c|}{$\geq 50(n=26)$} \\
\hline & No. & $\%$ & No. & $\%$ & No. & $\%$ & No. & $\%$ & No. & $\%$ \\
\hline \multicolumn{11}{|l|}{ Education } \\
\hline Illiteracy & 12 & 12.0 & 7 & 7.0 & 26 & 26.0 & 29 & 29.0 & 26 & 26.0 \\
\hline Primary school & 103 & 26.5 & 42 & 10.8 & 141 & 36.2 & 103 & 26.5 & 0 & 0.0 \\
\hline Middle school & 76 & 8.5 & 80 & 9.0 & 401 & 45.1 & 332 & 37.3 & 0 & 0.0 \\
\hline College or higher & 16 & 17.6 & 44 & 48.4 & 19 & 20.8 & 11 & 12.1 & 0 & 0.0 \\
\hline \multicolumn{11}{|l|}{ Job } \\
\hline Self-employed & 6 & 1.0 & 11 & 1.7 & 209 & 33.0 & 385 & 60.7 & 23 & 3.6 \\
\hline Builder & 8 & 11.0 & 23 & 31.5 & 38 & 52.1 & 4 & 5.5 & 0 & 0 \\
\hline Catering waiter & 177 & 72.0 & 29 & 11.8 & 30 & 12.3 & 7 & 2.8 & 3 & 1.2 \\
\hline Official & 2 & 2.7 & 8 & 10.8 & 43 & 58.1 & 21 & 28.4 & 0 & 0.0 \\
\hline Part-time job & 14 & 3.2 & 102 & 23.2 & 287 & 65.2 & 48 & 10.9 & 0 & 0.0 \\
\hline \multicolumn{11}{|l|}{ Monthly income (CNY) } \\
\hline Under 500 & 141 & 65.3 & 17 & 7.9 & 21 & 9.7 & 37 & 17.1 & 0 & 0.0 \\
\hline $500-2000$ & 60 & 5.9 & 106 & 10.4 & 417 & 40.9 & 415 & 40.7 & 26 & 2.6 \\
\hline $2000-5000$ & 6 & 3.2 & 41 & 21.7 & 123 & 65.1 & 19 & 10.1 & 0 & 0.0 \\
\hline Over 5000 & 0 & 0.0 & 13 & 30.2 & 26 & 60.5 & 4 & 9.3 & 0 & 0.0 \\
\hline
\end{tabular}

First, most of the respondents report receiving only standard education. The total illiteracy rate is $6.8 \%$, of which more females were found to be illiterate than males; the respondents aged 21-30 have better educational backgrounds, equivalent to college or higher. Second, most migrant Muslims either have set up a small business such as retail sale of ethnic food, clothes, and religious products, or employed as waiters in restaurants or builders in construction sites. Few work in white-collar jobs as officials. Many Muslim teenagers under 20 work in Muslim-owned restaurants, accounting for $72 \%$ of all respondents. Third, the monthly income of all migrant Muslims was found to be far below that of urban residents in Lanzhou (Lanzhou's Statistical Bureau 2016). Of the respondents, 43.8\% reported a monthly income ranging from $500 \mathrm{CNY}$ to $1000 \mathrm{CNY}$, making it difficult for them to keep a normal living. Furthermore, young migrants under 20 reported the lowest income; migrants with higher education generate more revenue. Overall, migrant Muslims in Lanzhou could be characterized as having lower education, less promotion, and less income than the average resident of Lanzhou, which, in some way, determine the spatial pattern of their dwelling. 


\subsection{Method}

Geographic information system (GIS) is well known for its advanced spatial analysis, exploring at a scientific level the spatial relationships, patterns, and processes of both physical and social phenomena. Spatial analysis using GIS provides a unique set of specialized techniques and models applicable to a wide range of research questions wherein the prime variables of interest vary significantly over space. The heart of spatial analysis is concerned with the analysis and modeling of spatial data. Spatial point patterns and spatial auto-correlation or correlation represent more appropriate perspectives for applications in the social sciences.

To demonstrate spatial distribution and pattern of the origins of migrant Muslims, mosques and Islamic restaurants in Lanzhou, their frequencies based on survey data are first gathered, and transferred to a GIS. Kernel density estimate (KDE), is then applied to the point data in order to generate a density in the current study for spatial point patterns to measure the frequency of variables above. KDE is not a statistical method to quantify clustering; instead, it generates comparable distribution maps of density on the frequency.

Intuitively, the kernel method consists of placing a kernel (density) over each observation point in the sample. A regular rectangular grid is superimposed on the data, and an estimate of the density is obtained at each grid intersection using information from the entire sample. The estimated density at each intersection is essentially the average of the densities of all the kernels that overlap that point. Observations that are close to a point of evaluation will contribute more to the estimate than will ones that are far from it. Thus, the density estimate will be high in areas with many observations, and low in areas with few.

The kernel density estimator for bivariate data is mathematically defined as

$$
\hat{f}(x)=\left[1 /\left(n h^{2}\right)\right] \sum_{i=1}^{n} K\left\{\frac{\left(x-X_{i}\right)}{h}\right\}
$$

Where $n$ is the number of data points, $h$ is the bandwidth, $K$ is a kernel density, $x$ is a vector of $x, y$ coordinates describe the location where the function is being evaluated, and $X_{i}$ is a series of vectors whose coordinates describe the location of each observation $i$.

\section{Results and Discussion}

\subsection{Comparatively Concentrated Origins of Migrant Muslims Dominated by two Ethnic Minority Regions}

Survey results show that migrant Muslims in Lanzhou come from the Gansu Province, making up 92\% of the total respondents. The first five origins of migrant Muslims are in turn Linxia Dongxiang Autonomous County, Linxia city, Tianshui Zhangjiachuan Autonomous County, Linxia Kangle County and Guanghe County. In terms of administrative division, Linxia Autonomous Hui Prefecture comprises one county-level city (Linxia) and seven counties (Linxia, Dongxiang, Jishishan, Guanghe, Kangle, Hezheng, and Yongjing). This data suggest that migrant Muslims in Lanzhou come from a few comparatively concentrated regions, dominated by two ethnic minority areas, namely, Linxia Autonomous Hui Prefecture and Tianshui Zhangjiachuan Autonomous County, which together account for $56.5 \%$ of the total. In contrast to migrant Muslims in Lanzhou, migrants in eastern metropolis, such as Beijing, Shanghai, Nanjing, Guangzhou and Shenzhen, come from all over the country with the purpose of obtaining more income and enjoying urban flourishing, regardless of geographical distance (Bai, 2007).

In demography, migration means an individual or a group move from one geographical space to another. Thus, regional transportation accessibility, such as interregional distance, regional traffic network and artery layout, can influence immigration. For example, Fan (2005) clarifies that the origins of females who in-migrated to Guangzhou for marriage are mostly distributed along railway lines between Guangxi and Guangdong Provinces. Based on a regression analysis by Li (2003), the volume of migrants from different regions in Shenzhen was found to be inversely proportional to the distance between Shenzhen and the corresponding region. British statistician E.G. Ravenstein (1885) proposes that migration or the volume of migrants is inversely related to the migration distance. The survey conducted for the current study conforms to this discipline. 938 of all respondents are from Linxia Prefecture, $160 \mathrm{~km}$ away from Lanzhou; 91 of them from Tianshui Zhangjiachuan, approximately $380 \mathrm{~km}$ from Lanzhou. Moreover, according to statistics, $80.7 \%$ of the habitual residences of the migrant Muslims from Linxia Autonomous Hui Prefecture are distributed within $20 \mathrm{~km}$ away from the 212 National Highway and the 309 Provincial Highway; 86.1\% of them from Tianshui Zhangjiachuan Autonomous County are distributed within $20 \mathrm{~km}$ from the 312 national highway and the 305 provincial highway. Evidently, convenient traffic reduces transportation cost, boosting the frequency of migration.

Economic factors are important in explaining why the economic difference between regions can lead to interregional migration. Linxia Hui Autonomous Prefecture is a southern courier station of the ancient Silk Road, once famed for its flourishing commodity trade. This was regarded as "Tea-Horse Trade Market" and "Dry Dock of Northwest China" 
(Linxia local chronicles, 1991). As early as the mid-1980s, the outstanding social activist Fei Xiaotong predicted that, "Wenzhou in east China and Hezhou (Linxia) in west China are two important commercial bases." The Muslims representing the Hui minority in Linxia have a strong sense of business, making them eager to leave their hometowns for the city in search of a better life. Although some Muslims greatly benefit from business, most live poorly due to bad harvests caused by their harsh natural environment. The disparity, particularly the economic development gap between two regions, usually causes a big push towards migration. In 2016, the GPD per capita of Linxia and Zhangjiachuan were in turn 1246 and $2728 \mathrm{CNY}$, respectively, which are correspondingly $4.9 \%$ and $12.4 \%$ of that of Lanzhou (Gansu Statistical Yearbook, 2016). Therefore, the large economic gap between the two regions can help explain the out-migration of the Muslims, especially to Lanzhou.

Social factors such as social relationships, lifestyle, community management, social approval, etc. are also important in explaining migration. According to demographer Everett S. Lee (1966), "the volume of migrants is in direct proportion to the heterogeneity between regions or crowds" The homogeneity in terms of identical ethnic religious culture, customs and lifestyle between sending regions and receiving regions has become a vital social factor that provokes Muslims' migration. According to Chinese sociologist Rong Ma (2004), "migration trends toward places inhabited by the same ethnic group in the hope of culture attribute and communication convenience. The small community dwelled by the same ethnic people can be developed autonomously which benefits to keep their traditional religion, custom and legitimate rights, and to help each other." According to R.L. Burford (1962), psychological distance is more important than geographical distance among the factors that determine migration. Aside from homogeneity, the proximity to religious activities is vital for Muslims to urge their migration. 110 places ( 89 mosques and 21 qubbahs) in Lanzhou have been erected for religious, thereby meeting the needs of migrant Muslims for religious and cultural activities. Homogeneity and proximity to religious activities help narrow the psychological distance between migrant Muslims at origin and Muslims at destination and increase their sense of acceptance to a city, pushing them even more to migrate.

\subsection{Typical Double “Core-Margin” Spatial Pattern and Change Caused by Traffic Improvement}

The KDE method of GIS is applied to measure the value of the frequency of 40 origins of migrant Muslims, which shows that the sources are dominated by Linxia prefecture and Zhangiachuan Hui Autonomous County, and two typical spatial distribution of the origins are revealed, namely, double "core-margin" structure and "string of bead" distribution along the traffic artery (Figure 3).

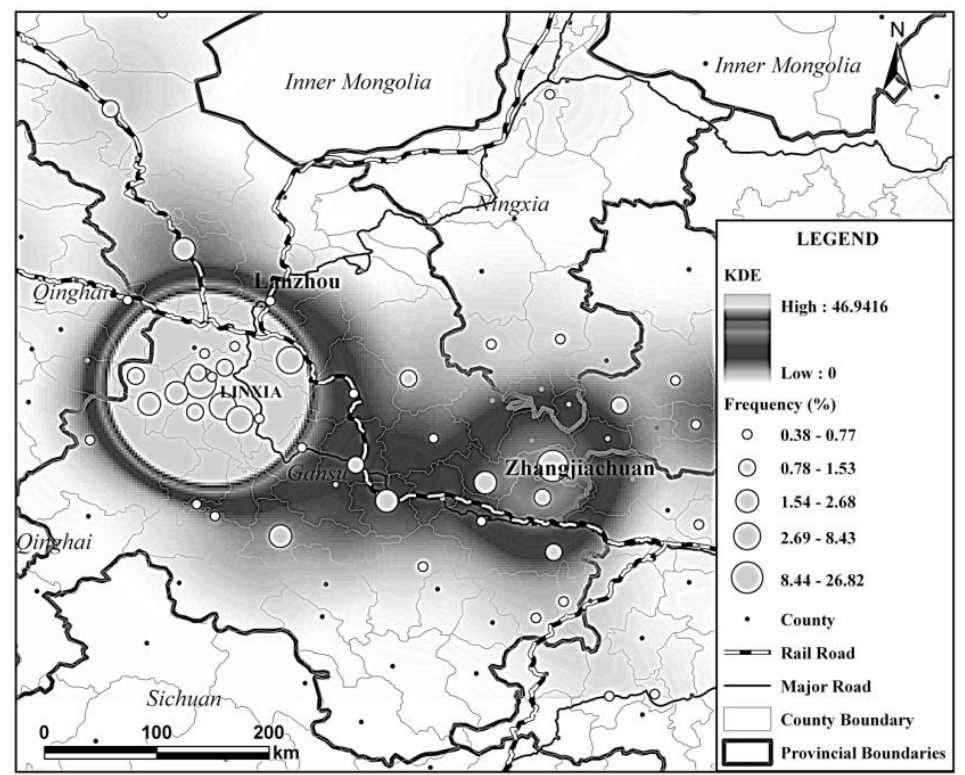

Figure 3. KDE for the frequency and spatial pattern of different origins

In the double "core-margin" structure, one "core" refers to the area that includes Dongxiang County, Linxia, Kangle County, Guanghe County. The other "core" refers to Zhangjiachuan County. The "margin" refers to other comparatively scattered sources with increasing distance from the core.

In contrast, most origins scattered within $20 \mathrm{~km}$ along the corresponding traffic artery exhibit a "string of bead" distribution pattern, which can lead to some changes to the double "core-margin" structure. The structure changes from basic "core-margin" to spindly "core-margin" and the major axis of the "core-margin" structure will extend, paralleling with traffic artery. The first structure corresponds to National Highway 212 and the second structure to the Longhai railway and National Highway 312. The traffic developments accelerate many Muslims to leave their hometown for large 
cities in search of a better life.

Actual regional migration is closely related to not only local potential scale of migrants but also local traffic facilities connected with Lanzhou. In terms of distance cost, the nearer to the traffic artery, the lower the migration cost. Moreover, traffic improvement can help enlarge the radius of migration. Ten years ago, $85 \%$ of the migrants from counties in Linxia Prefecture belonged to short-range migrants who first moved to Linxia, a local center for politics and economy, and then planned a new long-range migration after three years (Tang, 2006). However, currently, 97.3\% survey samples from Lanzhou have moved directly from their hometowns to Lanzhou. Thus, the reduction of transportation costs can stimulate one-off long-distance migration.

\subsection{Spatial Pattern as "Dwell Around Mosque" Is Weakening}

Lanzhou was one of important cities along ancient Silk Road. Tracing back to the Tang and Song dynasties, some Muslim traders had inhabited in Lanzhou. After rapid development during the Ming and Qing dynasties, a spatial structure referred to as "dwell- and work-around mosques" took shape (quoted from Blue National Religion Data Assemblies, 2003). Large Muslim communities emerged, including Gonglinlu, Jiangouyan, Xiaoxihu and Shangxiyuan.

As the obvious identification of Muslim communities, mosques are both a place for religious activities and a center for Muslims to engage in economy, culture, education, and good causes. The mosque is closely related to the day-to-day, as well as the social, activities of every Muslim family.

Table 2 shows that most migrant Muslims still like to dwell and work around mosques, thus, the traditional pattern of "live and work around mosques" have been remained in some way. However, $46.2 \%$ of dwellings and $50.1 \%$ of work places, respectively, are scattered, making it clear that the traditional structure is weakening. The evidences of detailed analysis below confirm this deduction.

Compared to the elderly, young migrants are more likely to reside away from mosques because they are less conscious of their nation, particularly those aged 21-30 are mostly dispersed. The cause lies in the fact that the young migrants are both open-minded and willing to live close to other non-Muslims. This willingness is influenced by many factors, including more frequent inter-ethnic interaction, social change, open-mindedness and personal independence. Moreover, the scattered residential trend of young migrants is likely to become still more evident in the future.

Table 2. Inhabitation of migrant Muslims in Lanzhou ( $\mathrm{N}=1467)$

\begin{tabular}{|c|c|c|c|c|c|c|}
\hline \multirow[b]{2}{*}{ Sample } & & \multicolumn{5}{|c|}{ Age, y } \\
\hline & & $\leq 20$ & $21-30$ & $31-40$ & $41-50$ & $\geq 50$ \\
\hline Characteristic & & No. $(\%)$ & No. $(\%)$ & No. $(\%)$ & No.(\%) & No. $(\%)$ \\
\hline \multirow[t]{2}{*}{ Inhabitation } & Around mosque & $91(44.0)$ & $62(35.9)$ & $342(58.3)$ & $269(56.6)$ & $26(100)$ \\
\hline & Scattered & $116(56.0)$ & $111(64.1)$ & $245(41.7)$ & $206(43.4)$ & $0(0.0)$ \\
\hline \multirow{2}{*}{$\begin{array}{l}\text { Change within } \\
\text { one year }\end{array}$} & Around a new mosque & 11(5.3) & $7(4.0)$ & $31(5.3)$ & 17(3.6) & $0(0.0)$ \\
\hline & $\begin{array}{l}\text { Around mosque to be } \\
\text { scattered }\end{array}$ & $25(12.1)$ & $34(19.7)$ & $49(8.3)$ & $15(3.2)$ & $0(0.0)$ \\
\hline
\end{tabular}

Note. "Around mosque" is within 1,000 meters

From July 2015 to July 2016, 189 migrant Muslims changed their modes of accommodation, 66 of them moved from an old mosque to a new one and 123 of them left their places of residence to be scattered in the city. This provides believable evidence of dwelling around mosques to weaken.

These migrant Muslims with less education or skill build small-scale businesses or work in blue-collar jobs. For instance, 43.2\% live off the retail sale of ethnic products such as Muslim-culture-focused food, clothes, worship, and special local products. $16.8 \%$ are waiters in Muslim-owned restaurants, and 5\% are builders. 54.2\% of these stores where migrant Muslims work are distributed closely around mosques. For example, a large market for retail sale and wholesale of ethnic products exists in Xiaoxihu, which is close to two big mosques: the Xihu mosque and the Shangxiyuan mosque. Among the 634 respondents who have their own businesses, 247 of them manage retail and wholesale businesses in this market. However, more than half of the working places of migrant Muslims are scattered. The significant reasons for decentralization include restaurants expanding to attract more customers and generate more profit, relocation due to urban planning, and the presence of commercial housing in new areas.

The place of residence of Muslim migrants often changed with the relocation of their working place. In 201620 larger mosques and 1560 Muslim-owned restaurants had been erected in Lanzhou. Figure 4 shows the spatial distributions and frequencies of the 20 bigger mosques and 1560 Muslim-owned restaurants in main built up areas of Lanzhou. Overall, a good spatial correlation does not exist in all areas, only in some areas, such as in Xiguanshizi, Xiaoxihu, Shangxiyuan, and Nanguan, where Muslim restaurants are clustered with mosques at the center. Most Muslim restaurants show a scattered distribution in space. 


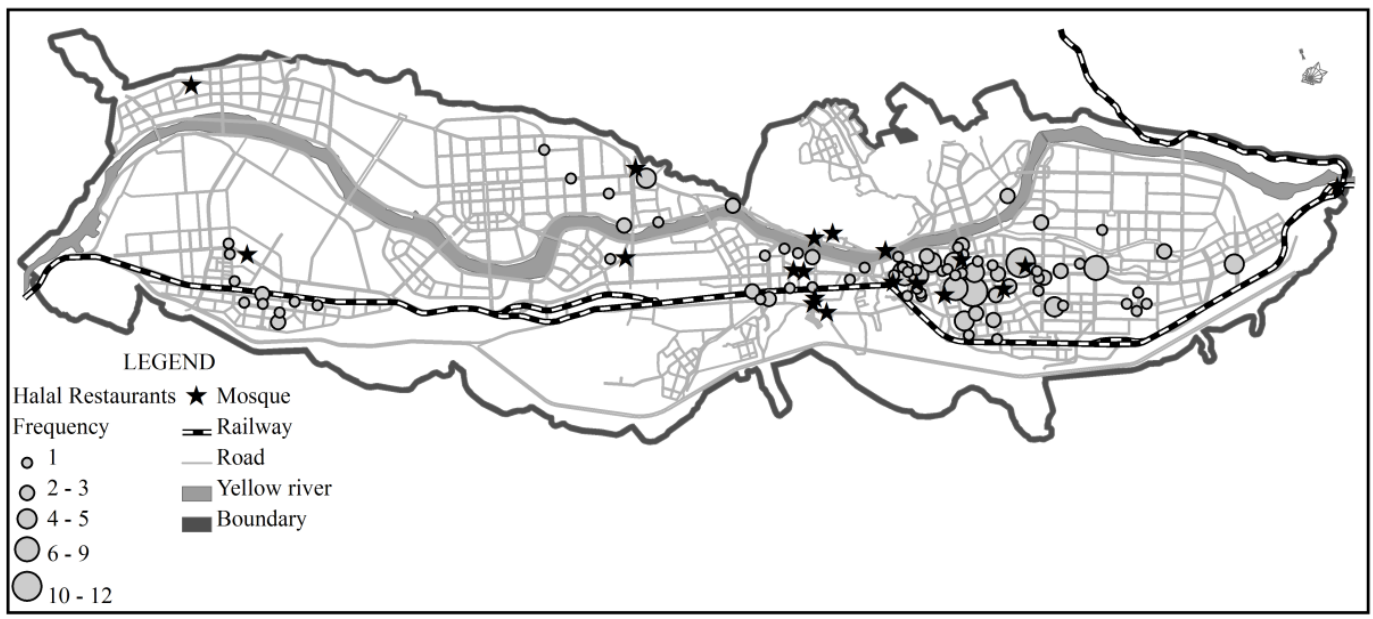

Figure 4. Spatial distributions of mosques and frequency of Islamic restaurants in downtown of Lanzhou

The increasing focus by migrant Muslims on the catering industry can bring about the spatial extension of the dwelling places. Today, the Muslims focused on catering makes up one third of the total catering industries in Lanzhou. There are approximately 3000 Muslim-owned catering enterprises and 1560 beef noodle restaurants, with 21000 employees. In the last ten years, Muslim-owned catering enterprises have expanded into large restaurant groups, such as Dongfanggong, Quanshunlou, Yunfeng, Yinfeng, and others. Each enterprise occupies up to $3000 \mathrm{~m}^{2}$ of land and turns over 10 million CNY (quoted from Lanzhou Bureau of Religious Affairs, 2016).

Larger Muslim-owned catering enterprises distribute their restaurants in densely populated areas, developing intense competition. Many restaurants need to be relocated away from mosques for better economic benefits. Apparently, many migrant Muslims who work in such restaurants are forced to live near their workplace to reduce expenses such as room rent and travel cost. These circumstances lead to the dispersion of the residence places of migrant Muslims.

In conclusion the spatial structure of the "dwell and work around mosques" concept regarding migrant Muslims in Lanzhou is steadily weakening.

\section{Conclusion}

1) The areas of origin of Muslim migrants in Lanzhou were relatively dominated by two ethnic areas, Linxia Autonomous Hui Prefecture. To a great extent, the ethnic homogeneity between the source place and Lanzhou city helps push migration. The 40 sources of migrant Muslims exhibit the structure of spatial distributions as double "core-margin" and "string of bead", and most sources scattered within $20 \mathrm{~km}$ along the corresponding artery. Traffic improvement can lead to some changes to the double "core-margin" structure from basic "core-margin" to spindly "core-margin" attenuated along corresponding artery.

2) The traditional pattern of "dwell around mosque" about migrant Muslims in Lanzhou is weakening. On the one hand, 46.2\% of migrant Muslims dwell away from mosque; on the other hand from July 2015 to July 2016123 migrants removed from their original places of residence The reason for decentralization includes the increasing spatial spread of Muslim-culture-focused catering, the weakening of traditional ethnic consciousness and the personal independence.

\section{Acknowledgement}

The work described in this paper was supported by the National Social Science Foundation of China (Grant No. 14BSH027) and by Belt and Road Special Project of Lanzhou University(Grant No. 2018ldbryb008) .

\section{References}

Alejandro, P., \& Min, Z. (1992). Gaining the upper hand: Economic mobility among immigrant and domestic minorities. Ethnic \& Racial Studies, 15(4), 491-522. https://doi.org/10.1080/01419870.1992.9993761

Bai, Y. T., \& Chen, B. C. (2007). Migrant Muslims and the Hui communities in large city. Journal of Hui Muslim Minority Studies, 4, 21-32.

Bai, Y. T., \& Chen, Y. C. (2007). Mobile Muslims and hui communities in large cities -- a case study of Nanjing, Shanghai and other cities. Hui studies, 4, 77-84.

Bugess, E. W. (1925). The growth of the city in R.E.Park, E W Bugess and Mckenize(eds.). The City University of Chicago Press. 
Burford, R. L. (1962). An Index of Distance as Related to Internal Migration. Southern Economic Journal, 29(2), 77-81. https://doi.org/10.2307/1054927

Ding, J. H., Liu, Z. Y., \& Cheng, D. M. (2005).Areal Differentiation of Inter-provincial Migration in China and Characteristics of the Flow Field. Acta Geographica Sinica, 60(1), 106-114.

E. G. Ravernstein (1885). The Laws of Migration. Journal of the Statistical Society of London, 48(2), 167-235. https://doi.org/10.2307/2979181

Everett, S. L. (1966). A Theory of Migration. Demography, 2, 47-57. https://doi.org/10.2307/2060063

Fan, C. C. (2005). Inter-provincial migration, population redistribution, and regional development in China: 1990 and 2000 census comparisons. The Professional Geographer, 57(2), 295-311. https://doi.org/10.1111/j.0033-0124.2005.00479.x

Fei, X. T. (1988). Fei Xiaotong Athology (pp 55-78). Tianjin: Tianjin People's Press.

Gao, X., Cheng, H. B., \& Yu, T. F. (2010). Adaptation to city for migrant Muslims in Lanzhou city. Chinese Journal of Population Science, 1, 101-110.

Homer, H. (1939). The structure and growth of residential neighborhoods in American cities(pp 12-20). New York:U.S. Government Printing Office.

J. S. Adams (1969). Directional Bias in Intra-Urban Migration. Economic Geography, 45(4), 302-323. https://doi.org/10.2307/142667

Jin, P. S., Wang, E., \& Zhang, W. X., et al (2007).Beijing residential suburbanization and the employment space dislocation. Journal of geography, 62(4), 387-387.

Jin, Z., \& Qiu, Y. H. (2009). China religion report (pp 4-10). Beijing: Social science literature press.

Li, R. J. (2003). An Analysis of Distribution of Floating Population in Guangzhou. Journal of Sun Yatsen University(Social Science Edition), 43(3), 73-81.

Linxia city local Chronicles compilation committee. (1997). Linxia city yearbook 1986-1995(pp 12-28).Lanzhou: Lanzhou university press.

Liu, S. (1999). The problem of floating population and urban "alien population". China population science, 4, 22-29.

Liu, W. B., Yan, X. P., \& Cao, X. S. (2010). Housing Type Variation and Its Influencing Factors in Transitional Urban China:Based on Analysis of CGSS 2005. Acta Geographica Sinica, 65(8), 949-960.

Lu, Q., Wang, G. X., \& Yang, C. Y. (2006). Some explanations to the relationships between the geographical distribution change of migrants and economic development change in regions of China, 1990 and 2000. Geographical Research, 25(2), 15-24.

Lu, Q., Wu, P. L., \& Lu, L. X. (2005). The relation between the characteristics of the migrants and economic development in Beijing and regional differentiation of their distribution. Acta geograhica Sinica, 60(5), 851-862.

Ma, R. (2004). Ethnic Sociology—study on Ethnic Groups relationship(pp 12-32). Beijing: Peking University Press.

Ma, R. (2004). Ethnic. Sociology—study on Ethnic Groups relationship(pp 33-45). Beijing: Peking University Press.

Michelson, W. (1977). Environmental Choice,Human Behavior, and Residential Satisfaction(pp 19-33).New York: Oxford University Press, 1977.

Murdie, R. A. (1969). Factorial Ecology of Metropolitan Toronto(pp 55-69).Chicago: University of Chicago.

Qian, Q. L., \& Chen, Y. B. (2003). Study over transient population settlement in megapolis with zhejiang villages of Beijing and Shipai area of Guangzhou as cases. Urban population, 27(11), 60-64.

Sun, B. D. (2008). An analysis of the impact of the balance of employment and living space in Shanghai on traffic and travel. China geographical society 2008 annual conference, 77-82.

Tang, D. X. (2006). An analysis of the characteristics of ethnic floating population in big cities of northwestern China: an example of Lanzhou city. Ethno-national Studies, 1, 31-42.

Wang, Y., \& Zhao, W. M. (2008). Socio-economic spatial structure based on RS and GIS --case study of Chongqing. Scientia Geographica Snica, 28(6), 729-735.

Wu, Q. Y. (1999). Research field and progress of urban social space differentiation. Journal of urban planning, 3, 23-26.

Wu, X., \& Wu, M. W. (2003). Comparison of domestic and foreign floating population settlements. Planner, 12, 96-101. 
Y. F. Tuan (1975). Place: An Experiential Perspective. Geographical Review, 65(2), 151-165. https://doi.org/10.2307/213970

Yao, H. S., Xu, X. Q., \& Xue, D. S. (2008). On Characteristics and Spatial Difference of Floating Populations in Guangzhou. Tropical Geography, 28(3), 259-264.

Zhang, W. Z., Liu, W., \& Li, Y. J. (2003). Housings" spatial distribution and residents" preference on housing location in Beijing. Geographical Research, 5(1), 73-77.

Zheng, S. Q., \& Cao, Y. (2009). The determining mechanism and influencing factors of the relationship between residential and employment space -- an empirical study on commuting time and commuting traffic in Beijing. Urban development research, 6, 29-35.

Zhou, S. H., \& Liu, Y. L. (2010). Spatial relations and changes of location selection in urban residential and employment areas in Guangzhou during the transitional period. Journal of geography, 65(2), 191-201.

\section{Copyrights}

Copyright for this article is retained by the author(s), with first publication rights granted to the journal.

This is an open-access article distributed under the terms and conditions of the Creative Commons Attribution license which permits unrestricted use, distribution, and reproduction in any medium, provided the original work is properly cited. 